\title{
PROFILE AND SCIENTIFIC CONTRIBUTIONS OF DOCTOR KEN'ICHI TAKEDA
}

\section{Wataru Nagata}

Shionogi Research Laboratory, Shionogi \& Co., Ltd., Fukushima ku, Osaka, 553 Japan

Doctor Ken'ichi Takeda was born on January 27, 1907 in Kamichikugo-machi, Nagasaki, as the first son of a banker. During his school days at the First High School, he became very interested in the organic chemistry of natural products, especially alkaloids. In 1928 he entered the Pharmaceutical Institute, Medical Faculty, Tokyo Imperial University (now the Faculty of Pharmaceutical Sciences, University of Tokyo) which was the mecca in Japan for organic chemists studying natural products at that time. His career as an organic chemist started at the institute under the guidance of Professor Heizaburo Kondo, head of the Laboratory of Pharmaceutical Chemistry, who was the successor of Professor Nagayoshi Nagai, one of the most distinguished organic chemists in Japan. Dr. Takeda became acquainted there with Professor Eiji Ochiai, who later succeeded Professor Kondo. Since then, both professors had been his lifelong advisers.

Dr. Takeda has been engaged in research for more than 40 years and has published 325 papers. His contribution of such a large number of papers is very admirable, considering his strenuous administrative duty as Director of Shionogi Research Laboratory for 22 years. His wide research interests include the chemistry of natural products 
such as terpenes, steroids, and alkaloids, the chemistry of heferoaromatics, and unit reactions such as cycloaddition and ring rearrangement.

The memorable theme of $\mathrm{Dr}$. Takeda's first research, started in 1930 under Professor $\mathrm{H}$. Kondo, was synthesis of the methylquinine analog $\underset{\sim}{3}$ from quinine (1) via quininone (2). This work was interrupted when Dr. Takeda graduated from the

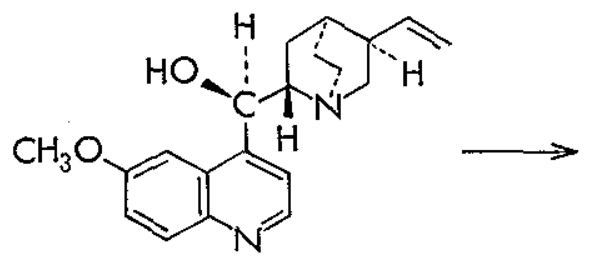

quinine (1)<smiles>C=CC1CN2CCC1CC2C(=O)c1ccnc2ccc(OC)cc12</smiles>

quininone (2)<smiles>C=CC12CC3CN(C1)C(C2)C3C(C)(O)c1ccnc2ccc(OC)cc12</smiles>

$\stackrel{3}{\sim}$

university in 1931. Twelve years later (1943), he resumed this research on quinine alkaloids at Itsuu Laboratory as wartime work. He studied the reaction of quinine and maleic anhydride as well as that of $\beta$-naphthol and maleic anhydride as model experiments. Study of the latter reaction led him to discover that phenolic aromatic hydrocarbons could undergo Diels-Alder reaction with various dienophiles.

After graduating from Tokyo Imperial University, Dr. Takeda worked as an assistant under Professor Kondo to start his professional career. His research was on the structural elucidation of lindenenol (4) (named linderene at first), linderane (5), and linderalactone (6), components of the Chinese drug Lindera strychnifolia Vill. 
<smiles></smiles>

lindenenol (4) (linderene)<smiles>Cc1coc2c1C1OCC3(C=O)OC(O2)C13</smiles>

linderane (5)<smiles>Cc1coc2c1C(C1=CC(C=O)=CCC1)CC2</smiles>

linderalactone (6)

Because the Kondo laboratory was concerned mainly with the chemistry of alkaloids at that time, Dr. Takeda had a difficult time studying the structure of lindenenol containing no nitrogen. The difficulty was enhanced by a tentative but wrong assignment of a furylfurane structure to lindenenol made by his predecessor. The structural study was expected to advance rapidly when Dr. Takeda isolated azulene on dehydrogenation of lindenenol in 1937, proving the compound was a sesquiterpene. However, most unfortunately this research was interrupted because he had to serve in the war in Central China for five years. The work was resumed at Itsuu Laboratory where he entered after returning in 1942. Itsuu Laboratory is a research foundation established for Professor Kondo with an investment by Gisaburo Shiono, the second President of Shionogi \& Co., Ltd. At the laboratory, where several former students of Professor Kondo were working, Dr. Takeda made significant progress in his strucfural study of lindenenols. He isolated and identified eudalene, 5-methyl-2hydroxynaphthalene, and dimethylbenzofuran 7 to establish the skeleton of lindenenol. This research was again interrupted a year later by wartime work on quinine alkaloids as mentioned earlier.<smiles>Cc1cccc2cc3occ(C)c3cc12</smiles> 
Dr. Takeda entered Shionogi Research Laboratory in April 1945, where he resumed his structural study of lindenenol in 1947 and continued until its absolute structure was finally elucidated as formula $\underset{\sim}{4}$ in 1966. Earlier studies were concentrated on the structural elucidation of linderazulene (8) and lindazulene (9).

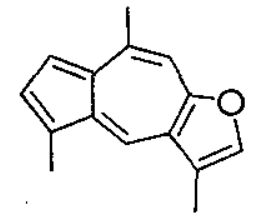

linderazulene $(\underset{\sim}{8})$

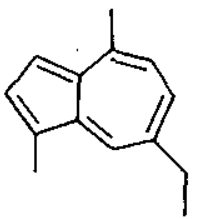

chamazulene (9)

(lindazulene)

The latter azulene was renamed chamazulene later, since both compounds proved to be identical. Their structures were elucidated in 1953 as shown in formulas $\underset{\sim}{8}$ and 9. Linderazulene was very unique in having an oxygen atom in the ring system, and its discovery has been very helpful to later structural studies of perhydroazulene-type sesquiterpenes carried out throughout the world. Isolation of chamazulene had been reported in the literature, but its structure was not known at that time. The structure was elucidated as norguajazulene $\underset{\sim}{9}$ separately by $\mathrm{Dr}$. Takeda and by Professor $\mathrm{F}$. Šorm in Czechoslovakia almost at the same time. Even after the dehydrogenation products had been clarified, the structure $\underset{\sim}{4}$ of lindenenol itself was not unveiled until nmr spectroscopy was used.

Dr. Takeda was successful consecutively in elucidating the structures of linderane (5) and linderalactone (6), the other major components of Lindera strychnifolia Vill., and also in isolating and elucidating the structures of 11 minor components, which were found to be sesquiterpenes having the furan ring. Linderalactone $(\underset{\sim}{)}$ of the 
germacrane type and isolinderalactone (10) of the elemene type were found to be interconvertible with retention of configuration in Cope rearrangement. This retention resulted from the existence of both compounds in sole, stable conformations.

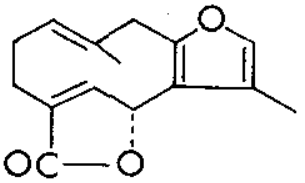

linderalactone (6)

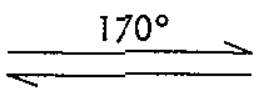

isolinderalactone $(\underset{\sim}{10})$

A similar germacrane-elemene interconversion can be seen in other furanosesquiterpenes. Investigating components of the domestic Lauraceae plants, Dr. Takeda isolated some furanosesquiterpenes from Neolitsea sericea and Neolitsea aciculata.

As mentioned earlier, the discovery of linderazulene, the first azulene having a furan ring, has greatly contributed to structure elucidation of sesquiterpenes of the perhydroazulene type. Ujacazulene (11), 3-demethyllinderazulene, was isolated as the second furanazulene on dehydrogenation of linderane (5). In view of the im-

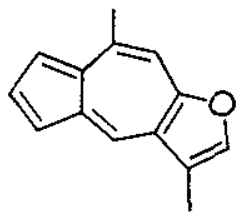

Ujacazulene (]1)

portance of these two furanazulenes, Dr. Takeda established their structures by total synthesis. Chamazulene $\underset{2}{q}$ also was synthesized. In an early stage of the structural study, the formation of these azulenes on dehydrogenation of lindenenol and its related compounds suggested that perhydroazulene was the skeleton of lindenenol. 
This suggestion led him to study conformational analysis and reactivities of sevenmembered ring compounds, especially of bicyclo $[5,3,0]$ decanes including guaiol, and the absolute configuration of guaiol-type sesquiterpenes. His continuing interest in sesquiterpenes as components of plants resulted in isolation and structural elucidation of many, new sesquiterpenes including carabrone, oplopanone, and liguloxide with new skeletons. He also studied biogenesis of these sesquiterpenes.

Dr. Takeda has contributed 87 papers in the field of sesquiterpenes; these studies constitute an important part of his life work. Especially, studies on components of Lindera strychnifolia Vill. and their related compounds unveiled sesquiterpenes of an entirely new type and added a new page in the history of terpene chemistry.

The other part of Dr. Takeda's life work lies in the field of steroids. His papers in this field amount to 157 . He started research on steroids in 1947 soon after entering Shionogi \& Co., Ltd., and is one of the pioneers in steroid research in Japan. According to his talk on "Recollections of My Researches" (Conference on Natural Products Chemistry, 1972), his interest in this field was induced by a suggestion of the late Professor Ochiai on the importance of steroids. Steroid research had been stimulated throughout the world in the 1940's by the discovery of adrenocortical hormones. His research on steroids which continued up to 1970 includes 1) studies on sapogenins, 2) modification of steroids, and 3) total synthesis of steroids.

Dr. Takeda's research on sapogenins, carried out for about 20 years from 1951 , was aimed at obtaining starting materials for preparation of corticoids from domestic plants. Intensive examination of components of Liliaceae, Dioscoreaceae, and 
Amaryllidaceae led to the discovery of more than 30 new sapogenins and elucidation of their structures. Of these sapogenins, metagenin (12), nogiragenin (13), meteogenin (14), and its epimer at $C_{25}$, neometeogenin, isolated from metanarthecium luteo-viride Maxim. (Japanese name: Nogiran) are the only known sapogenins having the hydroxyl group at $C_{11}$. Although sapogenins 12 and 13 , advantageous starting materials for preparation of corticoids, were successfully converted into corticosteroids, their industrial preparation could not be realized due to poor abundance of the plant. Other isolated sapogenins include ring-A polyhydroxysapogenins [kitigenin $(1 \beta, 3 \beta,-$

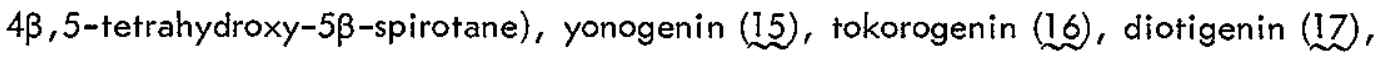
kogagenin (18)] and ring- $\mathrm{F}$ dehydro- or hydroxysapogenins [ convallamarogenin (19), reineckiagenin (20), isocarneagenin (21), and igagenin (22)]. Structures of these compounds were elucidated with the extensive aid of physicochemical techniques such as infrared spectroscopy, nuclear magnetic resonance spectroscopy, and optical rotatory dispersion (or circular dichroism). Without these techniques, discovery of unique sapogenins such as $12,13,19,20,21$, and 22 would not have been possible. In connection with biogenes is of the ring-F functionalized sapogenins $19-22, \mathrm{Dr}$. Takeda successfully converted normal sapogenins into these unusual ones using a . plant enzyme. His other phytochemically interesting contributions include: 1) characterization of sapogenins 15-18 from the Dioscoreaceae family as having the $3 a$-hydroxy group; 2) discovery that they exist in the form of free sapogenins in the aerial parts of the plants and as saponins in the underground parts; 3) study of the biosynthesis of 3a-hydroxysapogenins; 4) examination of the chemotaxonomy of the Dioscorea genus to clarify the relationship between its chemical constitution and morphological classification. 


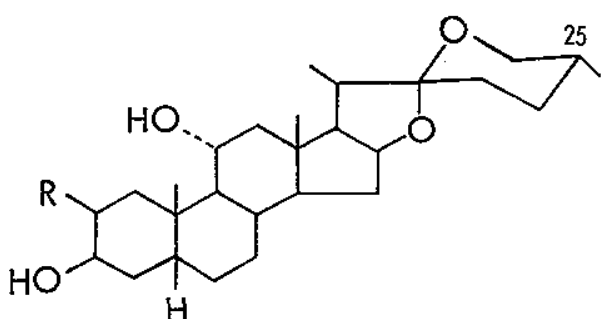

$\mathrm{H}$

$$
\begin{array}{ll}
\text { metagenin (12), } & \mathrm{R}=\mathrm{OH} \\
\text { nogiragenin (13), } & \mathrm{R}=\mathrm{H}
\end{array}
$$<smiles>Cc1cccc2c1C1CCCCC(C)C2CC1</smiles>

meteogein (14)

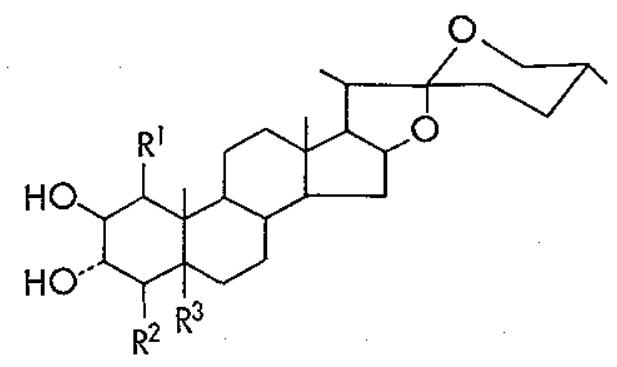

yonogenin (15), $\quad R^{1}=R^{2}=R^{3}=H$ tokorogenin (16), $\mathrm{R}^{1}=\mathrm{OH}, \mathrm{R}^{2}=\mathrm{R}^{3}=\mathrm{H}$ diotigenin (17), $\quad R^{1}=R^{3}=H, R^{2}=O H$ kogagenin (18), $\quad R^{\prime}=R^{3}=O H, \quad R^{2}=H$

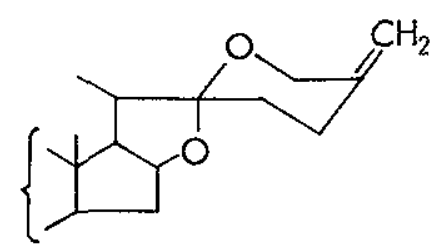

convallamarogenin (19) $(1 \beta-, 3 \beta-\mathrm{OH})$

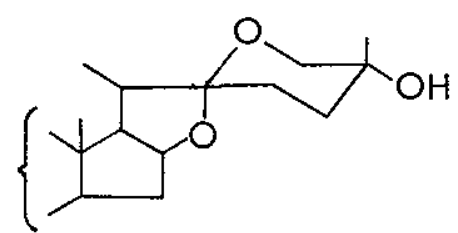

reineckiagenin (20) $(1 \beta-, 3 \beta-\mathrm{OH})$<smiles>CC1C2C3CC4CCCC(CC4)C3C2OC12CCC(CO)CO2</smiles>

isocarneagenin (21) $(1 \beta-, 3 \beta-\mathrm{OH})$ igagenin (22) $(2 \beta-, 3 \widetilde{\beta-O H})$

Dr. Takeda has extensively studied modification of steroids. He began his research in 1950 using bile acids which were easily available at that time. Two years later, he could prepare several conjugates of cholic acid (23) and amino acids, such as taurocholic acid (taurine + cholic acid) and glycocholic acid (glycine + cholic acid). In 1953, he published the first paper in his "bile acids and steroids" series on 
the conversion of hyodeoxycholic acid (24) (hog bile acid) into methyl 3-oxo- $\Delta^{4}-$ cholenate. This work was developed to the synthesis of progesterone (25) and deoxycorticosterone acetate (26) from hog bile acid. Another study on bromination of 7-oxocholanic acid led to synthesis of $3 a, 6 \alpha, 12 \alpha$-trihydroxycholanic acid.<smiles>CC1CCC(=O)OCCC2C3C(O)CC4C[C@@H](O)CCC4(C)C3C[C@H](O)C12C</smiles>

cholic acid (23)<smiles>CC(=O)C1CCC2C3CCC4=CC(=O)CCC4(C)C3CCC12C</smiles>

progesterone (25)<smiles>CC(CCC(=O)O)C1CCC2C3C[C@H](O)C4C[C@@H](O)CCC4(C)C3CCC12C</smiles>

hyodeoxycholic acid (24)<smiles>CC(=O)OCC(=O)C1(O)CCC2C3CCC4=CC(=O)CCC4(C)C3CCC21C</smiles>

deoxycorticosterone acetate (26)

Dr. Takeda's research on thiosteroids started in 1956 with infroduction of sulfurcontaining substituents into the steroid nucleus in an attempt to prepare an 11mercapto analog of hydrocortisone (27). Since 1960, he has reported syntheses of a number of steroidal episulfides at different positions via the cleavage products of the corresponding epoxides with thiocyanic acid or thioacetic acid. His attempt to prepare the 11-mercapto analog of hydrocortisone was in competition with a similar approach by Dr. Mossetig of NIH at that time. Both groups were not successful. On the other hand, $2 \alpha, 3 \alpha-e p i t h i o-5 \alpha-a n d r o s t a n-17 \beta-o l(28)$ and its cyclopentanone acetal 29 prepared by the above-mentioned method were found to possess anti- 
<smiles>CC12CCC(=O)C=C1CCC1C2C(O)CC2(C)C1CCC2(O)C(=O)CO</smiles>

hydrocortisone (27)<smiles>[R]OC1CCC2C1CCC1C2CCC2CC3SC3CC21C</smiles>

$\underset{\sim}{28}, R=H ， \underset{\sim}{29}, R=$

estrogenic activities and will soon be marketed as anti-mammary tumor agents. Another noteworthy contribution to thiosteroid chemistry was a joint study with Professor Djerassi of Stanford University on circular dichroism of steroidal thio derivatives such as episulfides, thiocyanates, thiol acetates, oxathiolanes, dithiocarbonates, trithiocarbonates, and dithioethylene ketals. This study demonstrated the relationship between the absolute configuration around the thio substituent and the C.D. parameters of the inherently dissymmetric sulfur chromophore. (For the details of his studies on thiosteroids, please refer to the contribution by Dr. Takeda himself in the present issue, $p . \quad$ ).

Based on the earlier prediction that total syntheses of steroids would become industrially important, Dr. Takeda started research on steroid total synthesis in 1957. The initial target molecules were aldosterone (30), the most potent mineral corticoid discovered by Professor Reichstein of Basel University, and its related corticoids . Therefore, the synthesis was designed to use 18-carbonitrile $\underset{24}{34}$ as the key intermediate, a possible intermediate for the functionalization at $C_{18}$ necessary for aldosteron synthesis. Intermediate 34 was prepared by an improved hydrocyanation method, and synthesis of dl-pregnenol (37) was achieved in 1959 by elaboration as shown in the following chart. 
<smiles>CC12CCC(=O)C=C1CCC1C(O)C3(C2)C(C(=O)CO)CCC13</smiles>

aldosterone (30)<smiles>COc1ccc2c(c1)CCC1C2CCC2=CC(=O)CCC21C</smiles>

31<smiles>CC1CCC2C(C)(C1)C1CCCC3(CCC(=O)CC23C)C1</smiles>

$\stackrel{33}{\sim}$<smiles>CC(=O)C[C@]1(C)CC[C@H]2CCCC[C@@H]1[C@H]2CC=O</smiles>

36<smiles>CC(=O)C1=CC[C@H]2CC3C4CCC5CC(O)CCC5(C)C4CCC13C2</smiles>

37

The synthesis, although not developed to an industrial process, was highly appreciated for its novel methodology and as the first steroid total synthesis in Japan.

As mentioned earlier, Dr. Takeda studied the reaction of $\beta$-naphthol and maleic anhydride first at Itsuu Laboratory during World War II and obtained a $1: 1$ adduct whose bridged structure 38 was left unconfirmed. The work was resumed soon after the war. Structural elucidation of the adduct was not easy at that time when modern physicochemical techniques had not been developed. The structure was finally established as $\underset{\sim}{38}$ by conversion of the adduct into the dihydro derivative 39 which 
was proved to be identical with an authentic sample prepared from the naphthalenemaleic anhydride adduct. The latter adduct was prepared and its structure was established by Dr. Kloetzel in the United States in 1950. Dr. Takeda presented his study on the Diels-Alder reaction of $\beta$-naphthol and maleic anhydride at the IUPAC congress held in Zurich, Switzerland in 1955. The reaction, which attracted much attention at the congress, was applied later to hydroquinone derivatives $\underset{\sim}{4 I}$ and $\beta-$ naphthol derivatives $\underset{\sim 3}{43}$, which were converted into adducts $\underset{\sim}{42}$ and $\underset{\sim}{44}$, respectively.

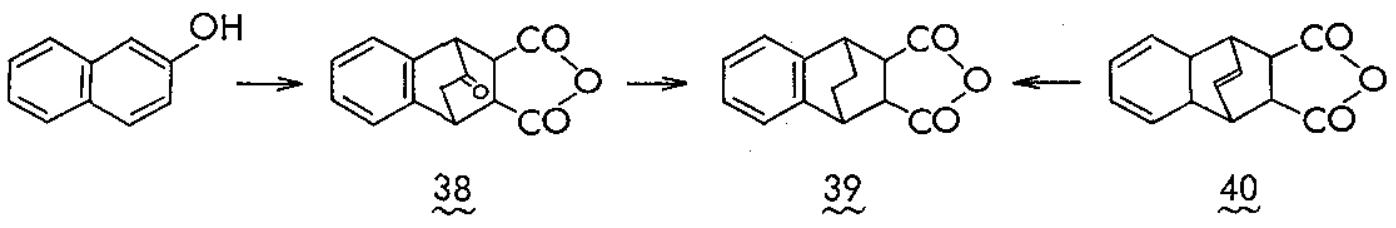<smiles>[R]c1cc(O)c([R])cc1O</smiles><smiles>[X]c1ccc2c(C)cc(O)cc2c1</smiles><smiles>[X]c1ccc2c(c1)C1C(C)C2C2COOOC21</smiles>
$\stackrel{41}{\sim}, R=H$ or $a|k y|$ $\stackrel{42}{\sim}$ 43 $\stackrel{44}{\sim}$ $X=5-, 6-, 7-, 8-\mathrm{OH}$ or $6-\mathrm{Br}$

These extended Diels-Alder reactions afford the products in higher yields compared with Kloetzel's reaction and provide an advantageous method for preparing bicyclo[ 2,2,2]octane derivatives.

Dr. Takeda's another noteworthy contribution is his research on lycoris alkaloids. Isolation of the alkaloids from Lycoris radiata HERB $\underline{\underline{E}}$ and their chemical degradations had been carried out by Professor H. Kondo's group from 1927 to 1933 . After the interruption during World War II, the alkaloid research was resumed by Professor Shojiro Uyeo of Osaka University (later a professor of Kyoto University), who made a 
significant progress in structure elucidation and syntheses of the lycoris alkaloids. Being a good friend of Professor Uyeo who also had worked under Professor Kondo, Dr. Takeda in 1952 decided to participate in the study of the chemistry of lycoris alkaloids, particularly on the stereochemistry of the alkaloids which had remained unsolved at that time. Four years later, he was successful in proposing structure $\underset{\sim}{46}$ or its mirror image for the absolute configuration of dihydrolycorine. Accordingly, that of lycorine was assumed to be $\underset{45}{4}$ or its mirror image. The stereochemical study was nicely carried out by applying the principles and concepts of stereochemistry, established in the steroid field, to lycoris alkaloids. On the basis of the configuration of lycorine, Dr. Takeda elucidated the configurations of caranine (47), pluviine (48), homolycorine (49), lycorenine (50), hippeastrine (51) and four isomers $(\alpha, \beta$, $\gamma$, and $\delta$ ) of lycorane (the skeletons of lycoris alkaloids) from 1958 to 1968 . The<smiles>OC1C=C2CCN3Cc4cc5c(cc4C(C1)C23)OCO5</smiles>

lycorine $(\underset{\sim}{45})$<smiles>OC1CC2CCN3Cc4cc5c(cc4C2(C1)[C@H](O)C3)OCO5</smiles>

dihydrolycorine (46)

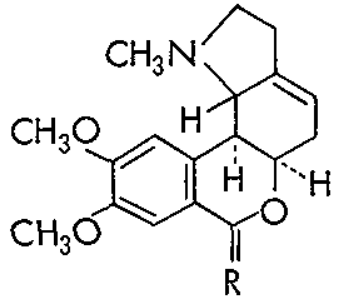

homolycorine (49), $R=0$ lycorenine (50), $\mathrm{R}=? \mathrm{OH}$<smiles></smiles>

hippeastrine (51)<smiles>[R9]Oc1cc2c(cc1O[R9])C13CN4CN1C=CC4=CCC(O)C23</smiles>

caranine (47)

$\mathrm{R}, \mathrm{R}^{\prime}=-\mathrm{CH}_{2}-$

pluviine (48)

$\mathrm{R}=\mathrm{R}^{\prime}=\mathrm{CH}_{3}$

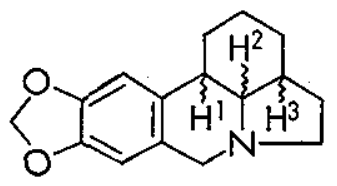

lycorane- $\alpha, \beta, \gamma, \delta(\underset{25}{)}$ 
absolute configurations of these alkaloids shown here were determined by study of their ORD or CD curves arising from the benzene chromophore. Dr. Takeda's other research accomplishments which are not described here include studies on: 1) components of Bupleurum falcatum L. as antimalarial agents, started in Central China with Professor Koichi Kimura of Shanghai Natural Science Laboratories and later resumed at Shionogi Research Laboratory, 2) thiazole derivatives in connection with vitamin $B_{1}$ synthesis, carried out for several years after the war, 3) biosynthesis of sapogenins using calus done recently, and 4) solvolysis of steroidal 1 la-tosylates.

We can not ignore Dr. Takeda's contribution to the development of Shionogi Research Laboratory as its Director. He was appointed to the position at the young age of 44 in 1951 (six years after entering Shionogi \& Co., Ltd.). Since then he endeavored to modernize the laboratories for 22 years until resigning in January 1973. His contribution is apparent from the present status of Shionogi Research Laboratory. The laboratories located in Fukushima-ku, Osaka and in Aburahi-cho, Shiga Prefecture are well equipped with modern facilities and employ about 1000 personnel. At the time of Dr. Takeda's appointment in 1951, the old laboratory had about 200 research personnel and was located in a small lot within the Kuise Plant in Hyogo Prefecture. The development of Shionogi Research Laboratory, although supported by the rapid growth of Shionoigi \& Co., Ltd. and stimulated by the growth of Japanese industries, is largely due to $\mathrm{Dr}$. Takeda's timely and vigorous efforts. In addition to development of the size and facilities, he encouraged the Shionogi scientists to develop their research abilities. Now Shionogi has many world-famous scientists including $\mathrm{Dr}$. Takeda himself in every field. Medicinal products developed or under development during his directorship include Sinomin (53) (Sulfisomezole, a world- 
famous, new sulfonamide drug), Dicetamin (54) (dicethiamine hydrochloride, a modified vitamin $B_{1}$ ), Acthormon (55) (giractide acetate, a synthetic ACTH), Thiodrol (28) (epistanol, an anti-esłrogenic agent) and Isoxal (궁 (perixazole citrate, an antiinflammatory analgesic).<smiles>Cc1cc(NS(=O)(=O)c2ccc(N)cc2)no1</smiles>

Sinomin (53) (sulfisomezole)<smiles>CCOC(=O)OCCC(SC(=O)OCC)=C(C)N(C=O)Cc1cnc(C)nc1N</smiles>

Dicetamin (54)

(dicethiamine hydrochloride)

Glycyl-L-tyrosyl-L-seryl-L-methionyl-L-glutamyl-L-histidyl-

L-phenylalanyl-L-arginyl-L-tryptophyl-glycyl-L-|ysyl-L-prolyl-

L-valyl-glycyl-L-|ysyl-L-lysyl-L-arginyl-L-arginine amide hexaacetate

Acthomon (55) (giractide acetate)

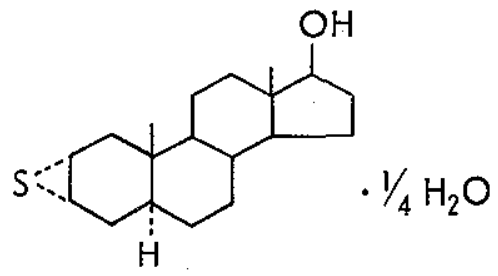

Thiodrol (28) (epitiostanol)<smiles>O=C(O)CC(CC(=O)O)CC(O)c1cc(-c2ccccc2)on1</smiles>

Isoxal (56) (perixazole citrate)

As soon as Dr. Takeda became Director, he reformed the old, rigid research system to a freer and flexible one to encourage the individual young scientists to develop their creative ideas as well as their ability to handle flexible research programs inherent to drug development. Dr. Takeda, a serious idealist, firmly 
believes that genuine, unique drugs can not be invented by mere imitation and urged the research personnel to participate in basic research as a rational approach to drug development. His unique attitude toward reseach seemed like that of one who aspired for truth and this was just what was necessary for Shionogi \& Co., Ltd. at that time. He believes that raising outstanding scientists will lead to oufstanding discoveries. According to this belief, he eagerly searched for good scientists throughout Japan in the fields of organic chemistry, physical chemistry, biochemistry, biology, and pharmacology, and encouraged all the Shionogi scientists to develop their scientific abilities. In his earlier days as Director, Dr. Takeda seemed to fully appreciate the old Japanese proverb "Man is a castle; man is a fort" (that is, instead of building a strong castle or fort, train your man properly). His first priority as Director was instilling a scientific discipline in the research personnel rather than the development of new medicines, and resulted in yielding many excellent scientists. In fact, he himself gave the Shionogi chemists seminars on "Electronic Theory of Organic Chemistry" by R. Robinson and C. K. Ingold as soon as it was introduced in Japan. Moreover, when the new research building was constructed in Fukushima-ku, Osaka in 1961, he held commemorative lecture meetings inviting a number of outstanding scientists in Japan and from abroad instead of giving the customary parties in celebration.

Dr. Takeda's academic contributions also are great in Japan and abroad. He has taught organic chemistry at many national universities as a visiting lecturer. He has been greatly helpful in establishing and developing domestic symposiums such as the Symposium on the Chemistry of Natural Products and the Conference on Natural Products Chemistry. He was an active member of the organizing committee for the 
IUPAC International Symposium on the Chemistry of Nafural Products held in Kyoto in 1964. He has been on the advisory board of "Tetrahedron Letfers" since its first publication in 1959. In the publication of "Heterocycles," the first international journal in organic chemistry published in Japan, he has provided Professor Tetsuji Kametani of Tohoku University, Editor, with pertinent advice and full support. According to Professor Kametani, the present issue was planned to be dedicated to Dr. Takeda to acknowledge his valuable contribution to the smooth development of this journal in honor of the seventieth anniversary of his birth. He has contributed and is continuing to contribute much to the development of the Pharmaceutical Society of Japan successively as director, supervisor, Vice-president, and President (1976).

Mountaineering and skiing have been Dr. Takeda's favorite sports since his school days. He knows the Japan Alps almost as well as his garden. At the age of 70 now, he continues to go skiing with his wife and several employees a couple of times every winter. He enjoys botanic excursions as did many Japanese natural product chemists in the early 20 th century. Certainly, knowledge of botany was an essential accomplishment for the earlier organic chemists who were mainly concerned with research on plant components. Dr. Takeda has urged us to appreciate the harmony and greatness of nature through botanization. He thinks that harmony is very important also in human society as well as in research laboratories.

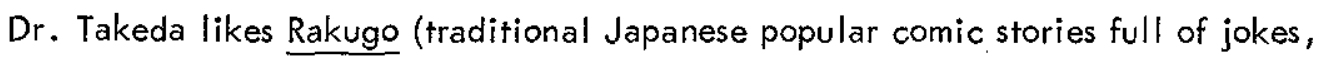
ironies, and tidbits of instruction), probably because he grew up in Tokyo where Rakugo is very popular. He used to pepper his conversations with his research staff with quotes from Rakugo. 
Dr. Takeda received the Pharmaceutical Society of Japan Award for Academic Contribution in 1961 for his work on the steroid total synthesis mentioned earlier. He was awarded the Director General of Science and Technology Agency Prize in 1962 for his contribution to the development of Sinomin. In 1972, the Blue Ribbon Medal was given to him for his contributions to Japanese industries.

Dr. Takeda is very healthy at the age of 70 now and is active as Managing Director of Shionogi \& Co., Ltd.

May he live long and happily! ACKNOWLEDGMENT: I am grateful to Dr. Katsumi Kotera, Dr. Hitoshi Minato, and Dr. Taichiro Komeno, former associates of Dr. Takeda, for providing me with the information for this article. I also thank Dr. Mitsuru Yoshioka for his help with the English. 